\title{
Da imprescritibilidade do direito humano fundamental ao devido processo legal, ao contraditório e à ampla defesa
}

From the imprescribility of the fundamental human right to due process, to contradictory and the broad defense

\section{De la imprescribilidad del derecho humano fundamental al debido proceso, a la defensa} contradictoria y amplia

\section{Resumo}

$\mathrm{Na}$ realidade processual brasileira, dentre os direitos fundamentais que mais se destacam estão os princípios do devido processo legal, do contraditório e da ampla defesa, especialmente alçados à categoria de direitos humanos agasalhados pelo texto da Constituição Federal, de 1988. Nesse sentido, torna-se indispensável analisar algumas questões ínsitas a referidos enunciados constitucionais, dada a importância de tais institutos para a estruturação e o desenvolvimento do processo de forma válida e regular, sem mácula de qualquer natureza. Para tanto, por meio de pesquisa científica, amparada em metodologia qualitativa de revisão bibliográfica, pretende-se, com este artigo, demonstrar a imprescritibilidade da pretensão material resultante de violação de direitos humanos fundamentais, independentemente do regime político democrático, autoritário ou totalitário vigente à época da prática do ato administrativo contrário à principiologia constitucional brasileira, recorrendo-se, inclusive, à pesquisa jurisprudencial, como forma de trazer à baila o entendimento do Superior Tribunal de Justiça (STF) a respeito da temática proposta, tendo em vista a extensão da repercussão jurídico-social que o pronunciamento de Tribunal Superior pode alcançar nos campos da interpretação e aplicação do direito positivo e nas relações da sociedade politicamente organizada.

Palavras-chave: Direitos fundamentais; Devido processo legal; Contraditório; Ampla defesa; Imprescritibilidade.

\begin{abstract}
In the Brazilian procedural reality, among the fundamental rights that stand out are the principles of due process, contradictory and broad defense, especially raised to the category of human rights listed by the text of the Federal Constitution of 1988. In this sense, it is indispensable to analyze some issues specific to these constitutional statements, given the importance of such institutes for the structuring and development of the process in a valid and regular manner, without stain of any nature. Therefore, through scientific research, based on qualitative methodology of bibliographic review, it is intended, with this article, to demonstrate the imprescriibility of material pretension resulting from violation of fundamental human rights, regardless of the democratic, authoritarian or totalitarian political regime in force at the time of the practice of the administrative act contrary to the Brazilian constitutional principle, using even jurisprudential research, as a way to bring up the understanding of the Superior Court of Justice (STF) regarding the proposed theme, in view of the extent of the legal and social repercussion that the pronouncement of the Superior Court can achieve in the fields of interpretation and application of positive law and in the relations of politically organized society.
\end{abstract}

Keywords: Fundamental rights; Due process; Contradictory; Broad defense; Imprescribility.

\section{Resumen}

En la realidad procesal brasileña, entre los derechos fundamentales que se destacan están los principios del debido proceso, la defensa contradictoria y amplia, especialmente elevados a la categoría de derechos humanos enumerados 
por el texto de la Constitución Federal de 1988. En este sentido, es indispensable analizar algunas cuestiones específicas de estas declaraciones constitucionales, dada la importancia de tales institutos para la estructuración y desarrollo del proceso de manera válida y regular, sin mancha de ninguna naturaleza. Por lo tanto, a través de la investigación científica, basada en la metodología cualitativa de revisión bibliográfica, se pretende, con este artículo, demostrar la imprescriibilidad de la pretensión material resultante de la violación de los derechos humanos fundamentales, independientemente del régimen político democrático, autoritario o totalitario vigente en el momento de la práctica del acto administrativo contrario al principio constitucional brasileño, utilizando incluso la investigación jurisprudencial, como una forma de llevar a colación la comprensión del Tribunal Superior de Justicia (STF) sobre el tema propuesto, en vista del alcance de la repercusión jurídica y social que el pronunciamiento del Tribunal Superior puede lograr en los campos de interpretación y aplicación del derecho positivo y en las relaciones de la sociedad políticamente organizada.

Palabras clave: Derechos fundamentales; Debido proceso; Contradictorio; Amplia defensa; Imprescribilidad.

\section{Introdução}

Torna-se oportuno, de começo, dizer que qualquer ato administrativo violatório dos direitos fundamentais do devido processo legal, do contraditório e da ampla defesa, acima de toda dúvida razoável, é absolutamente nulo e, como tal, afigura-se imprescritível a respectiva pretensão material, uma vez que o ato inválido, como é de conhecimento comum, não se convalida pelo decurso do tempo, eis que a administração pública direta e indireta de qualquer dos Poderes da União, dos Estados, do Distrito Federal e dos Municípios submete-se, em termos absolutos, a normatividade subordinante dos grandes princípios que informam e dão essência ao arcabouço jurídico nacional, notadamente os princípios de legalidade, impessoalidade, moralidade, publicidade e eficiência hospedados em previsão específica nos artigos 37, caput, do Estatuto Fundamental do Estado brasileiro.

Não se pode ignorar, em absoluto, que a administração pública direta e indireta de qualquer dos Poderes Institucionais dos entes subnacionais deve, sempre, observar as diretrizes legais na prática de ato estatal e, em igual medida, a tais princípios constitucionais estruturantes e norteadores da sua atividade-fim, pois, eventual desbordamento demandará a sua invalidação na ambiência administrativa (revogação ou nulidade) ou na judiciária (nulidade), até porque todos os atos administrativos são suscetíveis de controle jurisdicional de legalidade estrita, conquanto seja vedado ao Poder Judiciário substituir a administração pública para apreciar a motivação intestina da conveniência e oportunidade de ato discricionário.

Destaca, a propósito, que o que se busca, aqui, é demonstrar, de maneira clara, objetiva, específica e pormenorizada, a imprescritibilidade da pretensão material resultante de violação de direitos humanos fundamentais, independentemente do regime político democrático, autoritário ou totalitário vigente à época da prática do ato administrativo contrário à principiologia constitucional brasileira, valendo-se, para tanto, de seleta revisão bibliográfica com o intuito de apresentar a síntese dos apontamentos de natureza doutrinária e jurisprudencial acerca da reflexão temática proposta.

\section{Metodologia}

Para se abordar os temas afeitos ao constitucionalismo contemporâneo brasileiro, utilizou-se a metodologia de revisão bibliográfica, amparada em pesquisa de natureza qualitativa, visto que as reflexões aqui formuladas percorrem o âmbito da doutrina jurídica brasileira especializada, assim como se vale de entendimentos consignados no bojo de julgados oriundos de tribunal superior, notadamente o Superior Tribunal de Justiça (STF), também denominado Tribunal da Cidadania, tendo em vista que, em que pese a competência para processo e julgamento de casos em que se discute os contornos da aplicabilidade da legislação infraconstitucional, toda e qualquer interpretação do ordenamento jurídico processual percorre, necessariamente, os princípios de natureza adjetiva também estampados no texto da Constituição Cidadã.

De acordo com Gil (2002), a pesquisa bibliográfica é constituída pela análise de material-objeto que já encerrou seu processo de elaboração intelectiva, consistindo, em especial, na investigação de conteúdos presentes em livros e em artigos 
científicos, razão pela qual, nesta oportunidade, lançou-se mão de livros de referência na área jurídica como ferramenta destinada a delinear a essência teórica sobre a qual versa determinados pronunciamentos da instância superior do Poder Judiciário. Por conseguinte, a revisão da seleta bibliografia ora perscrutada foi indispensável para a compreensão das elucubrações técnico-jurídicas registradas no bojo dos julgados selecionados para a confecção do presente material.

De outra banda, a presença de julgamentos no teor do presente trabalho também se justifica em razão da amplitude que a reflexão jurídica individualmente destinada à solução de um caso concreto pode conferir à qualificação do debate coletivo sobre a matéria metodicamente retratada, partindo-se da aplicação individual do ordenamento positivo e seu arcabouço de princípios para se alcançar a extensão social do amplo sistema normativo, uma vez que, na esteira de Goldenberg (2004, p. 36), "cada indivíduo é uma síntese individualizada e ativa de uma sociedade, uma reapropriação singular do universo social e histórico que o envolve".

Desse modo, na investigação em tela, justifica-se o uso da pesquisa calcada em revisão de bibliografia como pressuposto para a análise jurisprudencial também desenvolvida, tendo em conta que, como dita acima, é a partir da síntese da normatividade individualmente realizada, por meio da interpretação e aplicação do Direito caso a caso, que se concebe as estruturas teóricas essenciais à reflexão jurídica mais ampla, aplicável a outros contextos pragmáticos e científicos, de modo a se entender com maior clareza as dimensões dos direitos fundamentais, mormente a base de princípios constitucionais amparada do devido processo legal, no contraditório e na ampla defesa.

\section{Resultados e Discussão}

É preciso que se diga, de início, que os direitos humanos fundamentais são o núcleo do constitucionalismo contemporâneo brasileiro, haja vista a previsão minuciosa dos direitos e garantias individuais, bem como toda a gama de preceitos de semelhante natureza, igualmente previstos, ainda que de forma esparsa, no bojo do Texto Maior, de 1988, tendo em conta, em especial, a primazia estabelecida pelos constituintes acerca da preservação das liberdades, impositivas de abstenção estatal no que diz respeito a qualquer exercício arbitrário dos poderes instituídos.

De todo modo, preambularmente, convém anotar que, para Moraes (2002, p. 39), os direitos fundamentais são definidos como "[...] o conjunto institucionalizado de direitos e garantias do ser humano que tem por finalidade básica o respeito a sua dignidade, por meio de sua proteção contra o arbítrio do poder estatal e o estabelecimento de condições mínimas de vida e desenvolvimento da personalidade humana".

Demais disso, os direitos humanos fundamentais, dentre eles o devido processo legal, o contraditório e a ampla defesa hospedados em previsão específica nos artigos $5^{\circ}$, incs. LIV e LV,§ $1^{\circ}$, e 60, $\S 4^{\circ}$, inc. IV, da Carta Magna Nacional, são inatos, universais, absolutos, inalienáveis e imprescritíveis, motivo por que qualquer transgressão a tais franquias constitucionais subjacentes à pessoa humana - que se revela extremamente grave, porque configura ofensa a uma das mais relevantes prerrogativas de ordem constitucional - não pode ser tolerada pelo Poder Judiciário brasileiro como instrumento concretizador das franquias constitucionais e dos direitos fundamentais assegurados pelos tratados e convenções internacionais subscritos pelo Brasil, sobretudo, quando lesivo a direito individual, o que, para além de qualquer dúvida razoável, séria e fundada, resulta do consenso doutrinário e jurisprudencial em torno do tema (Brasil, 2003; 2019).

É preciso salientar, volvendo ao tema em debate, que, ocorrendo a violação a direito fundamental de primeira geração ou dimensão de cidadão, civil ou militar, nasce, a partir daí, a imprescritível pretensão material de anular o ato estatal, pois, segundo assentou a primeira turma do Egrégio Superior Tribunal de Justiça, em sede recurso especial, in verbis:

A exigibilidade a qualquer tempo dos consectários às violações dos direitos humanos decorre do princípio de que o reconhecimento da dignidade humana é o fundamento da liberdade, da justiça e da paz, razão por que a Declaração 
Universal inaugura seu regramento superior estabelecendo no art. $1^{\circ}$ que 'todos os homens nascem livres e iguais em dignidade e direitos. (Brasil, 2004).

Embora, por outro lado, também se reconheça que

O instituto da prescrição tem por escopo conferir segurança jurídica e estabilidade às relações sociais, apenando, por via transversa, o titular do direito que, por sua exclusiva incúria, deixa de promover oportuna e tempestivamente sua pretensão em juízo. Não se concebe, nessa medida, que o titular do direito subjetivo violado tenha contra si o início, bem como o transcurso do lapso prescricional, em circunstâncias nas quais não detém qualquer possibilidade de exercitar sua pretensão, justamente por não se evidenciar, nessa hipótese, qualquer comportamento negligente de sua parte. (Brasil, 2014).

Sob essa ótica, conforme o magistério de Gomes (2001), é fácil constatar que qualquer ato estatal ofensivo a direitos fundamentais, carente de motivação e, portanto, imperfeito, não se convalida com o decurso do tempo, motivo por que, em tal caso, o Juiz não anula o ato, mas apenas declara a sua nulidade, já que é a própria lei que recusa emprestar validade ao ato inválido desde a sua origem, até porque “[...] os institutos da prescrição e decadência não se aplicam em situações que afrontam diretamente a Constituição Federal" (Brasil, 2015).

Na esteira das lições de Silva (2002), torna-se apropriado e útil dizer, sob esse ângulo, que é perceptível que qualquer ato administrativo que subtraia ou limite o exercício regular dos postulados essenciais do devido processo legal, do contraditório e da ampla defesa é nulo e o é porque essa nulidade, por vício insanável, advém da imperfeição que o caracterizou. Além disso, conforme aduz Pinto (2009), insta consignar que a imprescritibilidade da correspondente pretensão deve, assim, ser entendida, no sentido de que o titular do direito humano fundamental pode, em qualquer tempo, exigir seu direito público subjetivo, pois é à própria administração pública direta e indireta de qualquer dos Poderes da União, dos Estados, do Distrito Federal e dos Municípios quem compete aplicar a lei no caso concreto.

Seja como for, o certo é que a jurisprudência dominante do Egrégio Superior Tribunal de Justiça, como fonte nãoformal dos direitos humanos, entende - já que os anistiados políticos, civis e militares, foram reintegrados aos seus antigos cargos públicos e nesses aposentados ou transferidos para a reserva remunerada - como imprescritível a remanescente pretensão a indenização compensatória por dano moral presumido, então resultante da violação dos direitos humanos fundamentais durante o regime de exceção constitucional (31/03/1964 - 05/10/1988), conquanto o artigo $1^{\circ}$ do Decreto $n^{\circ}$ 20.910/1932, por sua vez, tenha estabelecido, como regra geral e sem excetuar às ações de reparação ex delicto ajuizadas em decorrência de perseguição, tortura e prisão por motivos políticos durante regime militar, o prazo prescricional de 5 (cinco) anos com relação a quaisquer direitos pessoais contra a Fazenda Pública; evidenciando, por conseguinte, que os atos de exceção são nulos e imprescritíveis, razão pela qual, deles não podiam - e nem podem - “advir qualquer efeito, ante a inexistência no mundo jurídico, a comprovar que as disposições desse ato normativo afiguram-se inaplicáveis, uma vez que o simples fato de se tratar de ente federado integrante da Fazenda Pública, por si só, não implica, necessariamente, na extinção da pretensão pela prescrição quinquenal" (Brasil, 2001).

Vê-se, daí, considerado o quadro normativo em que preponderam declarações constitucionais, que a supressão do devido processo legal, do contraditório e da ampla defesa constituem a negação arbitrária dos direitos fundamentais humanos, então elevados à categoria de cláusulas pétreas (cf. Arts. 5, incs. LIV e LV, § $1^{\circ}$, e 60, § $4^{\circ}$, inc. IV, da CRFB/1988), pois refletem - enquanto prática ilegítima, imoral, abusiva, ilegal e inconstitucional - um inaceitável ensaio de atuação estatal tendente a suprimir até mesmo a dignidade da pessoa humana com que o indivíduo foi dotado, de maneira indisponível, pelo próprio arcabouço jurídico nacional, sendo insuscetível, portanto, de dúvida, que qualquer ato administrativo, quando ofensivo aos direitos humanos fundamentais, será sempre considerado nulo e, em situação assim, não se convalida no tempo, não gera direito e a arguição da respectiva nulidade é sempre imprescritível, afinal de contas, sendo imprescritível o direito de ação para 
haver reparação de ato ilícito por violação a direito humano fundamental, com muito mais propriedade e por decorrência lógica, também o é para haver a desconstituição do próprio ato nulo que a efetivou (cf. Art. $8^{\circ}$, § $3^{\circ}$, do ADCT/1988).

Sabe-se, porém, não custa nada repetir que o artigo $8^{\circ}$ da Declaração Universal dos Direitos Humanos, então recepcionado formalmente pelo artigo $5^{\circ}$, $\S 2^{\circ}$ e $3^{\circ}$, da Magna Carta Federal, prevê, expressamente, que: "Toda pessoa tem direito a receber dos tribunais nacionais competentes remédio efetivo para os atos que violem os direitos fundamentais que lhe sejam reconhecidos pela constituição ou pela lei” (Brasil, 1948). Desse modo, franqueia-se o acesso à Justiça em seu sentido substancial, eis que as cláusulas do devido processo legal, do contraditório e da ampla defesa compreendem não apenas um conjunto de regras de caráter formal e substantivo destinado a assegurar a regularidade do processo judicial, parlamentar ou administrativo, mas também uma garantia material de que ninguém será arbitrariamente privado de seus direitos e liberdades.

Nesse sentido, a partir da ótica da jurisprudência, consagrou-se o entendimento de que, "Como se vê, o devido processo legal é a garantia maior do cidadão em face do arbítrio, dando-se a ele o direito, antes de ser submetido à sanção estatal, de ser submetido a um processo judicial cercado de garantias e precauções” (Brasil, 2012). Daí porque, consideradas as normas constitucionais pertinentes, maiores e melhores razões existem para concluir-se que "II - Inexistindo discricionariedade no ato disciplinar, o controle jurisdicional é amplo e não se limita a aspectos formais" (Brasil, 2008); o que, em certa medida, implica avaliação do motivo (fato) apresentado no ato de alijamento de servidor público ou militar dos quadros da Administração Pública, porquanto a via judicial é a única capaz de assegurar ao cidadão todas as garantias necessárias a um pronunciamento imparcial.

Nessa exata linha de intelecção e sem nenhuma derivação dialética, pode-se afirmar, com alto grau de certeza, e sob o ângulo da imprescritibilidade do direito humano fundamental ao devido processo legal, ao contraditório e a ampla defesa, que não se mostra possível ultrapassar a taxatividade do artigo $5^{\circ}$, incs. LIV e LV, da Carta Política do Brasil nem, tampouco, constituir distinguishing, overruling ou overriding apto, respectivamente, a afastar ou a superar total ou parcialmente o enunciado plasmado na Súmula Convencional/STF n ${ }^{\circ}$ 20, com relação a qual não cabe qualquer tergiversação, em obséquio ao princípio da certeza e da segurança jurídica.

É certo, todavia, que a imprescritibilidade não constitui regra no direito brasileiro, sendo admitida somente em hipóteses excepcionalíssimas que envolvam direitos da personalidade, estado das pessoas e bens públicos e, mais disso, que os demais casos devem se sujeitar aos prazos prescricionais do Código Civil ou das leis especiais. Não obstante isso, a prescrição quinquenal disposta no artigo $1^{\circ}$ do Decreto $n^{\circ}$ 20.910/1932 é inaplicável aos danos decorrentes de violação aos direitos humanos fundamentais por serem imprescritíveis, inclusive, nessa perspectiva, essa norma positiva interna conflita, em muito, com o artigo $8^{\circ}$ da Declaração Universal dos Direitos Humanos, da qual o Brasil é signatário desde 10 de dezembro de 1948, posto que equivale às emendas constitucionais (cf. Art. $5^{\circ}, \S 3^{\circ}$, da CRFB/1988) e, por conta disso e por força da sua hierarquia supralegal, sobrepõe-se a tal dispositivo legal no sistema jurídico nacional para conferir - com extrema densidade concreta - a imprescritibilidade da pretensão de anular todo e qualquer ato administrativo que menospreze os direitos humanos fundamentais, sendo, para tanto, "absolutamente desnecessário perquirir se o ato administrativo nulo vincula-se ao plano de existência (manifestação de vontade, idoneidade do objeto e finalidade) ou ao plano de validade (agente capaz, objeto lícito e forma prescrita ou não vedada em lei), eis que, na ambiência administrativa, não existe ato anulável" (Meirelles, 1966, p. 181).

Cumpre, entretanto, ter presente, também, que o Poder Judiciário, por força persuasiva do prevalecente princípio da inafastabilidade do controle jurisdicional (cf. Art. 5, inc. XXXV, da CRFB/1988) e também do princípio da prevalência da norma mais favorável ao cidadão (cf. Súmula Convencional/STF n n 654), deverá, sempre e sob o aspecto da legalidade estrita, reconhecer e proclamar que: "III - A Constituição da República não prevê lapso prescricional ao direito de agir quando se trata de defender o direito inalienável à dignidade humana, sobretudo quando violada durante o período do regime de exceção" (Brasil, 2018). Isso, a toda evidência, não vulnerará o princípio da divisão dos poderes institucionais encartado nos artigos $2^{\circ} \mathrm{e}$ 
60, § 4º, inc. III, da Constituição Federal/1988.

\section{Conclusão}

Como se deflui, de toda essa síntese, é possível constatar que, ante a histórica e salutar tarefa hermenêutica de aprimoramento do sistema normativo de proteção com vistas a adequar às exigências sociais e à realidade da vida, é generalizada, entre os juristas e juízes, a aceitação de que todas as leis escritas devem ser interpretadas, na atividade normal de sua incidência e na formação judicial das soluções das questões jurídicas judicializadas (Brasil, 2020). Do que se conclui, a rigor, que, dadas essas circunstâncias particulares, qualquer ato administrativo atentatório ao devido processo legal, ao contraditório e a ampla defesa, por força da teoria do controle jurisdicional do ato administrativo e de seus motivos, é manifestamente inválido e invalidável pelo Poder Judiciário, no controle jurisdicional de legalidade estrita (Cintra, 1979).

No mais, consoante Alvim (2019), aspecto de relevo que assoma é que isso decorre do fato inegável que a coerência e a logicidade do sistema jurídico dependem de uma atividade hermenêutica que não olvide a necessidade de se resguardar o princípio da proteção da confiança, dimensão subjetiva da segurança jurídica, devendo, pois, a administração pública dos Poderes do Estado brasileiro, por sua parte, agir com rigorosa observância aos princípios constitucionais implícitos e explícitos de legalidade, impessoalidade, moralidade, publicidade, eficiência, razoabilidade e proporcionalidade, notadamente em sua atividade sancionatória ou disciplinar, ante o dever estatal específico de proteção para os casos de violação que possui amplo lastro no ordenamento jurídico nacional \{cf. (Art. $8^{\circ}$ do CPC/2015) e (Art. $5^{\circ}$, inc. III, da CRFB/1988) \} e nas fontes normativas internacionais adotadas pelo Brasil (cf. Arts. $5^{\circ}$, $\S \S 1^{\circ}, 2^{\circ}$ e $3^{\circ}$, e $60, \S 4^{\circ}$, inc. IV, da CRFB/1988).

De se ressaltar, na linha de Abboud (2020), por fim, que é uma obviedade dizer que o instituto jurídico da prescrição não se sobrepõe ao da coisa julgada para fins do exercício regular do direito fundamental à jurisdição de envergadura legal e constitucional \{cf. (Art. $3^{\circ}$ do CPC/2015) e (Art. 5o, inc. XXXV, da CRFB/1988)\}, inclusive porque nenhum direito fundamental ou garantia constitucional é absoluto e não o é porque não pode ser interpretado de forma absoluta diante do conteúdo de outros direitos fundamentais e garantias constitucionais que, por sua vez, funcionam como limitadores recíprocos de uma interpretação irrestrita, e, mais disso, que não é possível, ao menos aqui, estabelecer uma concepção doutrinária incontroversa, insuscetível de questionamentos, exigindo-se, portanto, maior aprofundamento à eventual pacificação definitiva desta temática, o que, por conseguinte, mantém-se incompleto esse espectro de pesquisa científica, de modo que seja possível e recomendável, em investigações futuras, o desenvolvimento de estudos voltados à análise da possibilidade, ou não, de atribuição interpretativa do carácter absoluto e imprescritível a outros direitos fundamentais individualmente considerados no âmbito do ordenamento jurídico-constitucional brasileiro.

\section{Referências}

Abboud, G. (2020). Processo constitucional brasileiro. Revista dos Tribunais.

Alvim, T. A. (2019). Modulação na alteração da jurisprudência firme ou de precedentes vinculantes. Revista dos Tribunais.

Brasil. (1932). Decreto $n^{\circ}$ 20.910, de 6 de janeiro de 1932. Regula a prescrição quinquenal. http://www.planalto.gov.br/ccivil_03/decreto/antigos/d20910.htm

Brasil. Unicef. (1948). Declaração Universal dos Direitos Humanos. Adotada e proclamada pela Assembleia Geral das Nações Unidas (resolução 217 A III) em 10 de dezembro de 1948. https://www.unicef.org/brazil/declaracao-universal-dos-direitos-humanos

Brasil. (1988). Constituição da República Federativa do Brasil: promulgada em 5 de outubro de 1988. http://www.planalto.gov.b r/ccivil_03/constituição /cons tituicao.htm

Brasil. Superior Tribunal de Justiça. (2001). Recurso Especial $n^{o}$ 235449/MA. Rel. Min. Gilson Dipp, decisão monocrática. https://processo.stj.jus.br/pro cesso/revista/docu mento/mediado/?componente=MON\&sequencial=44854\&num_registro=199900957857\&data=20010626\&tipo=0

Brasil. Superior Tribunal de Justiça (2003). Recurso Especial $n^{o}$ 379414/PR. Rel. Min. José Delgado, Primeira Turma. https://jurisprudencia.s3.amazonaws.com/STJ/IT/RESP_379414_PR_1267665897763.pdf?AWSAccessKeyId=AKIARMMD5JEAO67SMCVA\&Expires=163 6056051\&Signature $=\% 2$ FlHIOPDrXUi6jOOY\%2FGQMtqzowtg\%3D 
Research, Society and Development, v. 10, n. 15, e427101523091, 2021

(CC BY 4.0) | ISSN 2525-3409 | DOI: http://dx.doi.org/10.33448/rsd-v10i15.23091

Brasil. Superior Tribunal de Justiça. (2004). Recurso Especial $n^{\circ}$ 612108/PR. Rel. Min. Luiz Fux, Primeira Turma. https://scon.stj.jus.br/S CON/GetInteiro TeorDoAcordao?num_registro=200302108787\&dt_publicacao=03/11/2004

Brasil. Superior Tribunal de Justiça. (2008). Mandado de Segurança ${ }^{\circ}$ 12983/DF. Rel. Min. Felix Fischer, Terceira Seção. https://scon.stj.jus.br/SCON/Ge tInte iroTeorDoAcordao?num_registro=200701695599\&dt_publicacao=15/02/2008

Brasil. Superior Tribunal de Justiça. (2012). Recurso Especial $n^{\circ}$ 1307407/SC. Rel. Min. Mauro Campbell Marques, Segunda Turma. https://scon.s tj.jus.br/SCO N/Ge tInteiroTeorDoAcordao?num_registro=201200287073\&dt_publicacao=29/05/2012

Brasil. Superior Tribunal de Justiça. (2014). Recurso Especial $n^{\circ}$ 1347715/RJ. Rel. Min. Marco Aurélio Bellizze, Terceira Turma. https://scon.stj.jus.br/SCO N/GetInteiroTeorDoAcordao?num_registro=201201917415\&dt_publicacao=04/12/2014

Brasil. Superior Tribunal de Justiça. (2015). Agravo Regimental no Recurso Especial $n^{\circ}$ 1502071/GO. Rel. Min. Humberto Martins, Segunda Turma. https://scon.s tj.jus.br/SCON/GetInteiroTeorDoAcordao?num_registro=201402966620\&dt_publicacao=24/03/2015

Brasil. Superior Tribunal de Justiça. (2018). Recurso Especial n ${ }^{\circ}$ 1565166/PR. Rel. Min. Regina Helena Costa, Primeira Turma. https://scon.stj.jus.br/SCO N/GetInteiroTeorDoAcordao?num_registro=201502802959\&dt_publicacao=02/08/2018

Brasil. Superior Tribunal de Justiça. (2019). Recurso Especial $n^{o}$ 1783581/RS. Rel. Min. Herman Benjamin, Segunda Turma, https://scon.stj.jus.br/SCON/GetInteiroTeorDoAcordao?num_registro=201803214242\&dt_publicacao=01/07/2019

Brasil. Superior Tribunal de Justiça. (2020). Recurso Especial n $n^{\circ}$ 1814919/DF. Rel. Min. Og Fernandes, Primeira Seção. https://scon.stj.jus.br/SCON/GetIn teiroTeorDoAcordao?num_registro=201901403897\&dt_publicacao=04/08/2020

Cintra, A. C. de A. (1979). Motivo e motivação do ato administrativo. Revista dos Tribunais.

Gil, A. C. (2002). Como elaborar projetos de pesquisa. Atlas.

Goldenberg, M. (2004). A arte de pesquisar: como fazer pesquisa qualitativa em ciências sociais. Record.

Gomes, O. (2001). Introdução ao direito civil. Forense.

Meirelles, H. L. (1966). Direito administrativo brasileiro. Revista dos Tribunais.

Moraes, A. de. (2002). Direitos humanos fundamentais. Atlas.

Pinto, A. G. G. (2009). Direitos fundamentais: legítimas prerrogativas de liberdade, igualdade e dignidade. Revista da EMERJ, 12 (46), p. 126-140.

Silva, J. A. da. (2002). Curso de direito constitucional. Malheiros. 